\title{
A IMPORTÂNCIA DAS MACRÓFITAS AQUÁTICAS NO CICLO DO MERCÚRIO NA BACIA DO RIO TAPAJÓS (PA)
}

\author{
Sérgio A. Coelho-Souza, Márcio R. Miranda \& Jean R.D. Guimarães
}

Lab. Traçadores Wolfgang Christian Pfeiffer, Inst. Biofísica Carlos Chagas Filho, Universidade Federal do Rio de Janeiro (UFRJ), Bloco G CCS, Rio de Janeiro, CEP 21941-902, Brasil. Emails: sacs@biof.ufrj.br; topo@biof.ufrj.br; jeanrdg@biof.ufrj.br

\section{RESUMO}

Os estudos sobre o ciclo do mercúrio (Hg) na região amazônica durante os últimos 20 anos indicam que a atual fonte de contaminação do meio aquático é o desmatamento. O Hg que se deposita no sistema terrestre tem grande afinidade com os oxihidróxidos de Ferro $(\mathrm{Fe})$ e Alumínio ( $\mathrm{Al}$ ), que são carreados por lixiviação durante o período de chuvas. Esses elementos integram o material particulado fino (MPF) e são acumulados em raízes de macrófitas aquáticas, principal local de formação do metilmercúrio $(\mathrm{MeHg})$, composto neurotóxico biomagnificado na cadeia trófica. Durante o período de cheia, a inundação da floresta fornece material orgânico, ácidos húmicos e fúlvicos e $\mathrm{Hg}$ junto com sedimentos argilosos, que formam um ambiente favorável à metilação biótica e abiótica do Hg. As condições reduzidas e de $\mathrm{pH}$ ácido podem favorecer a biodisponibilidade do $\mathrm{Hg}$ e a diversidade e atividade de microrganismos podem intensificar o processo de transferência trófica do $\mathrm{MeHg}$ produzido. Durante o período de seca, as macrófitas se decompõem e o Hg, possivelmente, retorna aos sistemas atmosférico e terrestre.

Palavras-chave: Formação de Metilmercúrio, Desmatamento da Amazônia, Ciclo de Inundação, Águas claras, Ciclo Biogeoquímico do Mercúrio.

\begin{abstract}
THE IMPORTANCE OF AQUATIC MACROPHYTES IN MERCURY CYCLE IN TAPAJOS RIVER (PA). Studies about the mercury $(\mathrm{Hg})$ cycle in the Amazon region indicate that deforestation is a main source of $\mathrm{Hg}$ to aquatic systems. The atmospheric $\mathrm{Hg}$ deposits in soil have a great affinity with Iron $(\mathrm{Fe})$ and Aluminum (Al) oxyhidroxides that are carried to waters by runoff during rainy season. Constituting the fine particulate matter (FPM), Hg is accumulated in aquatic macrophytes roots, a main site of methylmercury ( $\mathrm{MeHg}$ ) production, permitting biomagnification of the neurotoxic MeHg. During wet season, the organic material, humic and fulvic acids and $\mathrm{Hg}$ associated to clayed sediments from inundated forest seem to intensify biotic and abiotic $\mathrm{Hg}$ methylation. The reducing and acidic conditions may facilitate the bioavailability of the reactive $\mathrm{Hg}$ and a higher transference of the produced $\mathrm{MeHg}$ is expected as a function of microbial activity and diversity. During the dry season, $\mathrm{Hg}$ may return to the atmospheric and terrestrial systems as a consequence of macrophyte decomposition.
\end{abstract}

Keywords: Methylmercury production, Amazon deforestation, flood cycle, clear waters, Mercury biogeochemical cycle.

\section{INTRODUÇÃO}

O mercúrio $(\mathrm{Hg})$ é um dos metais pesados mais tóxicos e apresenta algumas particularidades. É mais comumente encontrado como mercúrio metálico $\left(\mathrm{Hg}^{0}\right)$, além do mercúrio mercuroso $\left(\mathrm{Hg}^{+}\right)$e o mercúrio mercúrico $\left(\mathrm{Hg}^{++}\right)$. Suas diferentes formas físicas o tornam um problema global, já que este metal pode ser encontrado em estado gasoso na forma de mercúrio elementar $\left(\mathrm{Hg}^{0}\right)$ e dimetilmercúrio $\left[\left(\mathrm{CH}_{3}\right)_{2} \mathrm{Hg}\right]$, dissolvido na forma de mercúrio mercúrico $\left(\mathrm{Hg}^{++}\right)$ ou associado ao material particulado, e em formas orgânicas como o metilmercúrio. É justamente a forma orgânica metilada, o metilmercúrio (MeHg), a mais relevante devidoà sua alta toxicidade, biomagnificação e por ser formada em ambiente aquático (ICPS 1990). São as especiações químicas do $\mathrm{Hg}$ que controlam os efeitos ecológicos e toxicológicos deste metal no sistema aquático. Vários fatores físicos, químicos $\mathrm{e}$ biológicos determinam os processos de transformação 
e especiação do Hg. Assim, existe uma dependência das condições ambientais para que o $\mathrm{Hg}$ inorgânico seja convertido a MeHg (Ullrich et al. 2001).

No Brasil, o problema relacionado à contaminação de mercúrio foi marcante na década de 80 durante a corrida de ouro na região amazônica (Cleary \& Thornthon 1994). Orio Tapajós, importante afluente do rio Amazonas, foi um dos principais locais estudados em relação à prática de garimpagem e a contaminação por mercúrio (Villas-Boas et al. 2001). Hoje em dia, a mineração de ouro decresceu expressivamente, porém os níveis de mercúrio continuam elevados, possivelmente devido ao intenso desmatamento e transporte do $\mathrm{Hg}$ para o sistema aquático (Roulet et al. 1998b, 1999, 2001a, Lacerda et al. 2004). $\mathrm{O}$ processo de metilação do $\mathrm{Hg}$ ocorre biótica e abioticamente, tendo-se destacado, em ambientes temperados, na camada superficial do sedimento de fundo (Craig 1985). Em clima tropical, as raízes de macrófitas apresentam maior potencial de metilação do que outras matrizes aquáticas (Guimarães et al. 1998, 2000b, Mauro et al. 1999, 2002, CoelhoSouza et al. 2006a). Na bacia do rio Tapajós, as raízes de macrófitas aquáticas apresentaram maior metilação e atividade bacteriana do que o sedimento superficial (Coelho-Souza et al. 2006b, Miranda et al. 2004), além de maior formação de $\mathrm{MeHg}$ quando comparada com material em suspensão, plâncton e algas filamentosas (Guimarães et al. 2004). Este trabalho sugere a hipótese de que há um acúmulo de Hg pelas raízes de macrófitas durante o período de chuvas, maior metilação e transferência de $\mathrm{MeHg}$ na cheia e decréscimo de biomassa e decomposição das raízes durante a seca (Figura 1).

\section{POSSÍVEIS FONTES DE MERCÚRIO}

Foram indicadas algumas fontes de mercúrio no sistema amazônico durante a última década, entre as quais, a que recebeu maior atenção foi o intenso uso de mercúrio em atividades mineradoras de ouro durante a década de 80. O processo de amalgamação envolve o despejo de mercúrio metálico no sistema aquático e posterior queima liberando mercúrio volátil elementar. A prática de amalgamação tem mais de 4500 anos (Malm 1998). Em 1993, Pfeiffer e colaboradores estimaram que 130 toneladas de $\mathrm{Hg}$ eram lançadas na região amazônica por ano durante a década anterior.
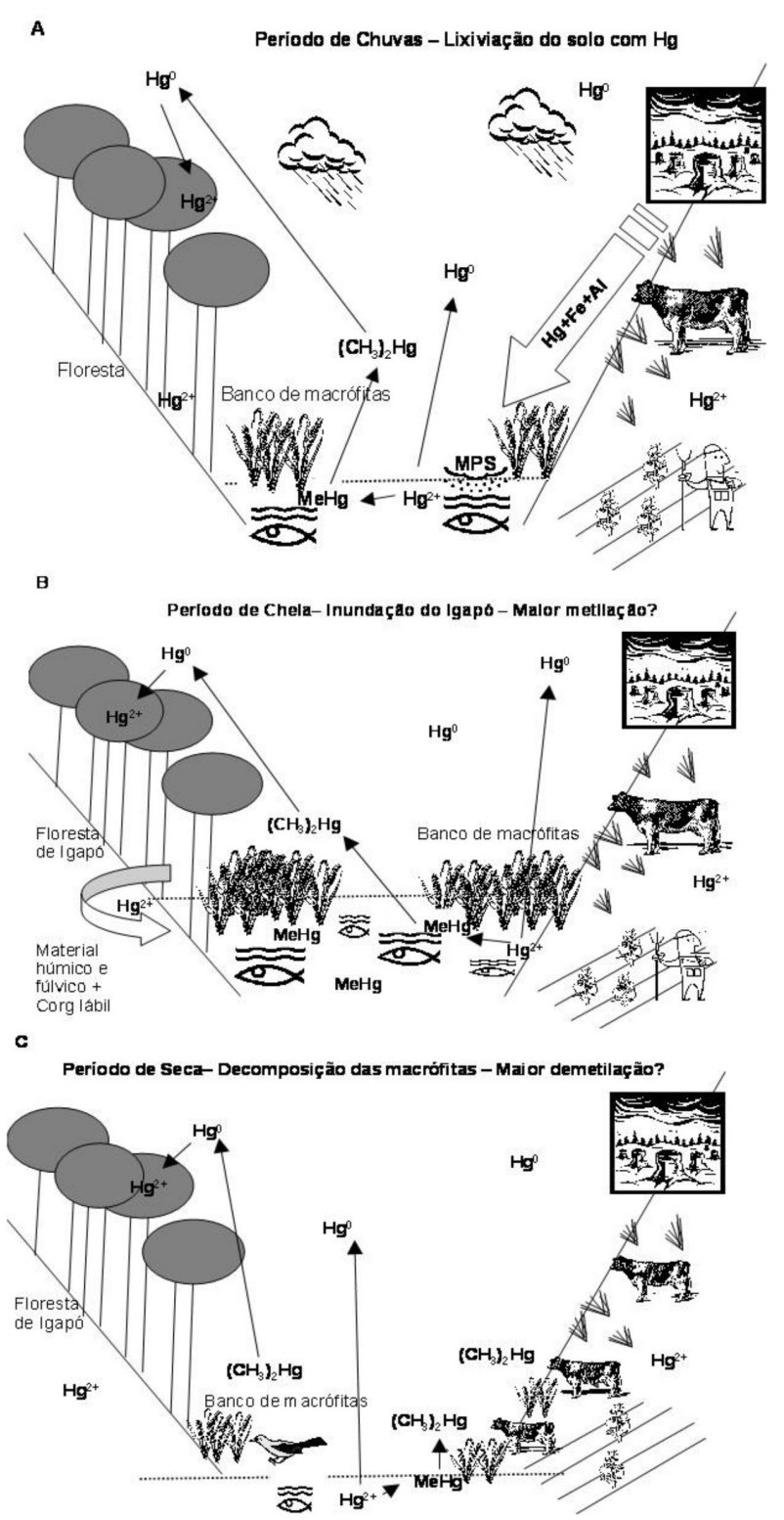

Figura 1. Hipótese do ciclo biogeoquímico do mercúrio na bacia do rio tapajós. A) $\mathrm{O}_{\mathrm{Hg}^{2+}}$ deposita no meio terrestre e é lixiviado durante o período de chuvas associado à oxihidróxidos de $\mathrm{Fe}$ e Al, constituindo o material particulado em suspensão (MPS) que pode precipitar e/ou ser acumulado por raízes de macrófitas aquáticas. B) Durante a cheia, o igapó inundado fornece matéria orgânica lábil e $\mathrm{Hg}^{2+}$ ao perifíton associado às raízes e pode intensificar o processo de formação de $\mathrm{MeHg}$. Maior biomassa de macrófitas e da biodiversidade aquática podem favorecer a biomagnificação do $\mathrm{MeHg}$. C) Na seca, a decomposição das macrófitas pode beneficiar o retorno do $\mathrm{Hg}$ aos sistemas terrestre e atmosférico.

A queimada intensa da região amazônica também foi sugerida como uma importante fonte de mercúrio atmosférico (Veiga et al. 1994, Lacerda 1995), sendo que essas práticas continuam correntes na Amazônia. Cordeiro et al. (2002) apresentaram uma correlação positiva entre o fluxo de mercúrio e a produção de ouro, a produção de partículas de carvão e, com a evolução de indicadores de queimada de florestas e a produção doméstica bruta. 
O tempo de residência do $\mathrm{Hg}$ na atmosfera pode variar de alguns meses a dois anos, o que permite a sua dispersão global. Lindqvist et al. (1985) estimaram que apenas $10-20 \%$ do $\mathrm{Hg}$ emitido por fontes pontuais se deposita nas proximidades das mesmas, o restante sendo depositado regional ou globalmente. O mercúrio pode se depositar por via húmida ou seca no solo amazônico, e a grande afinidade com os oxihidróxidos de ferro e alumínio presentes, permite seu acúmulo no meio terrestre (Roulet \& Lucotte 1985). Roulet et al. (1998a) calcularam que mais de $97 \%$ do mercúrio acumulado nos solos amazônicos são pré-antropogênicos, sendo o solo um importante reservatório natural. $\mathrm{O}$ desmatamento intenso e a conseqüente erosão parecem ser os principais fatores de contaminação de $\mathrm{Hg}$ no meio aquático, transportado junto com o material particulado fino para a bacia hidrográfica (Roulet et al. 1998b, 1999, 2001a).

\section{O MERCÚRIO NO SISTEMA TERRESTRE}

Na floresta amazônica ao longo do rio Tapajós, Roulet et al. (1999) verificaram que a concentração de $\mathrm{Hg}$ (ng/g peso seco) variava entre 3 e 198 em folhas frescas, 35 e 154 em mistura de rizomas, 53 a $153 \mathrm{em}$ húmus, 5 a 48 em caules e ramificações, 9 a $19 \mathrm{em}$ raízes, 51 a 127 em serrapilheira, 7 a 66 em troncos em decomposição e, em solo, entre 90 e $210 \mathrm{ng} / \mathrm{g}$ de peso seco (Roulet et al.1998b). Poirier (2004) não encontrou diferença na concentração de $\mathrm{Hg}$ total em solos naturais e em pastos. Ambos variaram entre 20 e $140 \mathrm{ng} / \mathrm{g}$, porém em locais de pastagem de gado, as menores concentrações de $\mathrm{Hg}$ foram observadas na base do morro, quando comparadas com o topo. Além do mais, a média da concentração de Hg total foi maior em latossolos (solos com textura argilosa) do que em solos podzólicos (ácidos e com textura arenosa), variando respectivamente entre 39 e 213 e 23 e 188ng/g (Figura 2). Farella (2005) considerou o desmatamento o evento mais importante na variação de conteúdo de $\mathrm{Hg}$ no solo. Após a retirada da mata, foram observadas respostas similares em relação ao conteúdo de matéria orgânica, fertilidade do solo e acúmulo de $\mathrm{Hg}$ em solos com distintos usos. Em outras palavras, o desmatamento é o fator mais importante de perda de $\mathrm{Hg}$ pelos solos do que os usos subseqüentes dos mesmos.

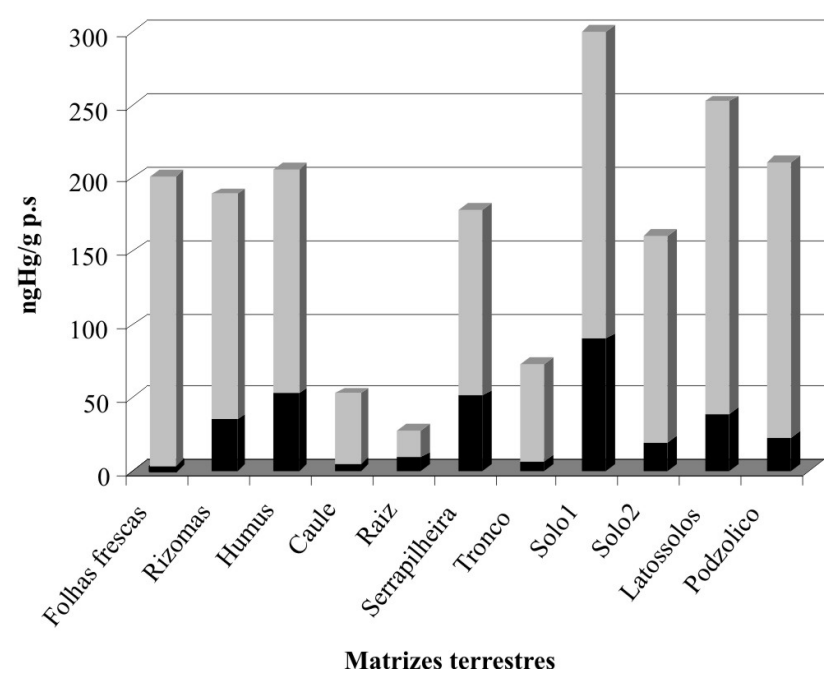

Figura 2. Concentrações de mercúrio total (mínima em negro e máximo em cinza) em diferentes matrizes terrestres reportadas por Roulet et al. (1998b, 1999) e Poirier (2004).

\section{O MERCÚRIO NO MEIO AQUÁTICO: AS MACRÓFITAS COMO UM IMPORTANTE ELO ENTRE O MERCÚRIO INORGÂNICO E ORGÂNICO}

O Hg depositado no solo integra o material particulado fino e pode ser carreado para o sistema aquático devido à lixiviação do solo após o desmatamento (Roulet et al. 1998b, 1999, 2001a). Na bacia do rio Tapajós, a concentração de Hg na água parece ser determinada pela concentração de partículas em suspensão. A concentração de $\mathrm{Hg}$ na fração particulada fina $(0,6-29,7 \mathrm{ng} / \mathrm{L})$ pode representar 40 $90 \%$ da concentração volumétrica total de $\mathrm{Hg}$ (Roulet et al. 2001a). As águas do rio Tapajós apresentaram níveis de $\mathrm{Hg}$ total entre $3,4-4,1 \mathrm{ng} / \mathrm{L}$ enquanto que em lagos inundados a variação foi entre 2 - 3ng/L, nas épocas de seca e de chuva, respectivamente (PachecoPeleja 2002), sugerindo maiores valores de $\mathrm{Hg}$ durante as chuvas. Por outro lado, em água filtrada e material particulado, os maiores valores de $\mathrm{Hg}$ foram observados no período de seca, variando entre 0,432,8ng/L e 0,28-13,1ng/L, respectivamente (Roulet et al. 1998a). No material em suspensão e plâncton, o $\mathrm{Hg}$ total variou entre $43-430 \mathrm{ng} / \mathrm{g}$ na porção $<40 \mu \mathrm{m}$ e entre 48-320ng/g no plâncton $>40 \mu \mathrm{m}$ (PachecoPeleja 2002). Em sedimentos superficiais localizados em bancos de macrófitas aquáticas, a concentração de $\mathrm{Hg}$ observada foi entre $0,84-1,5 \mathrm{ng} / \mathrm{L}$, enquanto em Igapó variou entre 1,31-2,6ng/L (Roulet et al. 1998a). Porém, no perifíton associado a raízes da 
macrófita Paspalum repens a concentração variou entre 67 e 200ng/g, entre as estações de cheia e de chuva, respectivamente (Coelho-Souza et al. 2006b). $\mathrm{O}$ processo de biomagnificação é observado por Sampaio da Silva e colaboradores (2005) onde os peixes não piscivoros apresentaram uma variação de concentração de $\mathrm{Hg}$ em músculo entre $55-130 \mathrm{ng} / \mathrm{g}$ durante a cheia e entre $27-210 \mathrm{ng} / \mathrm{g}$ no período de chuvas, e os peixes piscívoros entre 370-590ng/g e 370-540ng/g, respectivamente (Figuras 3 e 4). Assim como no sistema terrestre, a variação da concentração de $\mathrm{Hg}$ total nos diferentes locais do meio aquático também foi expressiva. Os peixes representam a principal fonte protéica para a população ribeirinha e foram observados níveis de $\mathrm{Hg}$ em cabelo de humanos variando entre $4-20 \mu \mathrm{g} / \mathrm{g}$, com menores valores entre aqueles que incluem frutas tropicais em sua dieta (Passos et al. 2003).

O material particulado fino é o local que apresenta maior concentração de $\mathrm{Hg}$ total no sistema aquático, sendo acumulado nas raízes das macrófitas aquáticas e transformado em MeHg. A formação do metilmercúrio aumenta a biodisponibilidade do $\mathrm{Hg}$ e, consequentemente, sua dispersão no ambiente, pois apresenta reduzida afinidade com as superfícies minerais do sedimento (Melamed et al. 1997). O MeHg produzido é liberado para a água e entra na cadeia trófica por rápida difusão e, também por forte ligação às proteínas da biota devido à sua elevada afinidade com os grupos sulfidrila (tióis). Assim é rapidamente acumulado, atingindo altas concentrações nos tecidos dos peixes do topo da cadeia alimentar (IPCS 1990).

$\mathrm{O}$ ciclo de inundação parece ter grande influência sobre o ciclo do Hg (Coelho-Souza et al. 2006b). As macrófitas aquáticas podem ser o elo entre o aumento ou diminuição da metilação do Hg. Recentemente, foi sugerido que durante o período de chuvas, a composição do perifíton associado às raízes de macrófitas é determinada pela erosão do solo de áreas desmatadas, uma vez que é a principal fonte do material particulado fino (MPF) para o meio aquático. $\mathrm{O} \mathrm{MPF}$ contendo $\mathrm{Hg}$ associado à oxihidróxidos de $\mathrm{Fe}$ e Al seria acumulado pelo perifíton, resultando em um maior acúmulo deste metal (Figura 1a). No período de cheia, o perifíton parece receber maior influência do carbono mais lábil proveniente dos Igapós inundados, aumentando a diversidade, densidade e atividade de microrganismos presentes nas raízes. Um maior potencial de metilação e biomassa de macrófitas são observados e, a maior diversidade biológica pode intensificar a transferência trófica e, conseqüente biomagnificação do $\mathrm{MeHg}$ (Figura 1b). No período de seca, a biomassa de macrófitas decresce, iniciando o processo de decomposição das raízes no sistema terrestre, sendo a parte seca muitas vezes utilizada por gado e aves (Figura 1c). Lemos (2001) sugeriu que detritos antigos em processo de decomposição estimulam a taxa de demetilação, diminuindo a concentração de $\mathrm{MeHg}$.

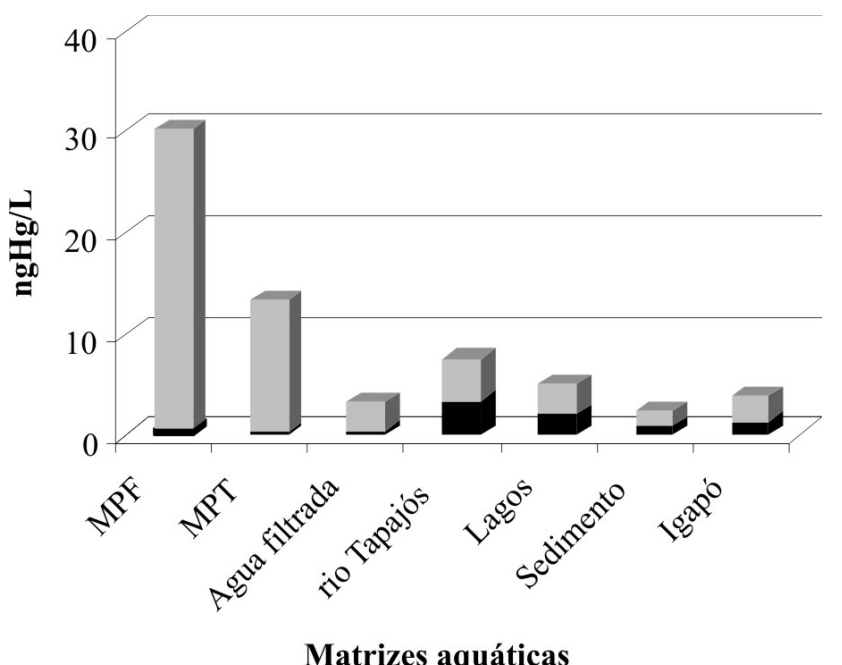

Figura 3. Concentrações de $\mathrm{Hg}$ total (ng/L) em distintas matrizes do meio aquático (mínima em negro e máxima em cinza). $\mathrm{MPF}=$ material particulado fino, MPT $=$ material particulado total. Sedimento $=$ calculado pela razão do Hg particulado total (mg/L). Dados de Roulet et al. 1998a, 2001a, Pacheco-Peleja 2002.

\section{FATORES QUE PODEM INFLUENCIAR A FORMAÇÃO DE METILMERCÚRIO EM RAÍZES DE MACRÓFITAS AQUÁTICAS}

Segundo Ullrich et al. (2001), a especiação química do Hg é o principal fator determinante no potencial de metilação de um sistema e pode ser influenciada por uma variedade de fatores ambientais. A eficiência da metilação microbiana geralmente depende de fatores como a atividade heterotrófica e a concentração de $\mathrm{Hg}$ biodisponível, mais do que o acúmulo de $\mathrm{Hg}$ total. A especiação do $\mathrm{Hg}$, por sua vez, é dependente de parâmetros como temperatura, $\mathrm{pH}$, potencial redox e a presença de complexos orgânicos e inorgânicos. A produção de $\mathrm{MeHg}$ geralmente está relacionada a pH e salinidade baixos e a presença de matéria orgânica lábil em ambientes reduzidos. Admitindo uma influência do ciclo de inundação nos fatores reguladores do 
ciclo do Hg, algumas sugestões são apresentadas para melhor compreensão do complexo processo de formação de $\mathrm{MeHg}$ no perifíton associado a raízes de macrófitas aquáticas da bacia do rio Tapajós.

\section{COMPOSIÇÃO BIOLÓGICA DO PERIFÍTON}

A formação abiótica do $\mathrm{MeHg}$ mais estudada é a que ocorre com a metilcobalamina (Craig 1985), substâncias húmicas e fotoquimicamente(Weber 1993) e, no processo biótico, através da ação enzimática de microrganismos (Ullrich et al. 2001). Porém, é difícil distinguir o processo biótico do abiótico no ambiente, pois muitas moléculas doadoras de radicais metil estão disponíveis, principalmente como produtos de processos biológicos. Os organismos metiladores são, usualmente, dotados de maior resistência ao mercúrio e seus compostos (Kelly et al. 1995). Assim, além da influência biótica, a metilação abiótica (Weber 1993), os parâmetros abióticos (Mauro et al. 1999) e as condições anaeróbicas (Regnell \& Tunlid 1991) são fatores químicos influenciando o metabolismo de bactérias na formação de MeHg. Segundo Weber (1993), os agentes químicos metiladores mais abundantes no ambiente são os doadores metil $\mathrm{Me}^{+}$ do (dimetilsulfonio)propionato (DMSP), comumente associado a plantas aquáticas. A metilação biótica parece ser mais relevante que a abiótica em ambientes dulcícolas e estuarinos e, em ambientes temperados, as bactérias mais ativas na metilação são as que apresentam orientação metabólica sulfato-redutora (Craig 1985, Compeau \& Bartha 1985, Gilmour \& Henry 1991). O papel das bactérias redutoras de sulfato (BRS) é surpreendente devido à ampla faixa de microrganismos capazes de metilar o $\mathrm{Hg}$ em culturas e em sedimento (King et al. 2000, 2001, 2002). Entretanto, nem todas as bactérias redutoras de sulfato são capazes de metilar o mercúrio (Choi et al. 1994) e muitos outros microrganismos já apresentaram capacidade de formar $\mathrm{MeHg}$ (CoelhoSouza et al. 2006a, Barkay \& Wagner-Döbler 2005, Ullrich et al. 2001).

$\mathrm{Na}$ lagoa costeira e eutrofizada da Lagoinha (Rio de Janeiro), o uso de inibidor metabólico específico para esse grupo de bactérias reduziu significamente a metilação em raízes de Eichhornia crassipes (Guimarães et al. 2006, Mauro et al. 2001). Por outro lado, utilizando a técnica radioquímica para medir taxa de redução de sulfato (Rosser \& Hamilton 1983, Ulrich et al. 1997), Coelho-Souza (2003) observou que enquanto a taxa de redução de sulfato foi expressiva em raízes de Eichhornia crassipes na Lagoinha (com inibição de $24,5 \%$ na presença de oxigênio), a mesma foi abaixo do limite de detecção nas raízes de Paspalum repens das águas claras e oligotróficas de lagos do rio Tapajós. O uso de inibidores específicos indicou a participação de outros tipos de microrganismos na metilação, havendo relações de interdependência, e cujas abundancias e atividade variam de acordo com o local de coleta da macrófita aquática (Guimarães et al. 2006).

A eutrofização pode estar relacionada com maior concentração de sulfato, composto que apresenta baixa concentração nas águas claras da Amazônia (cerca de $70 \mu \mathrm{Eq} . \mathrm{L}^{-1}$ ), assim como vários outros elementos (Furch \& Junk 1997). Nielsen et al. (2004) reportaram baixa atividade redutora de sulfato no sedimento de um lago amazônico com águas claras e concentração de sulfato correspondente a $35 \mu \mathrm{M}$, contrastando com $500 \mu \mathrm{M}$ de sulfato em sedimentos de uma lagoa costeira eutrofizada. A produção de metano foi a principal via de mineralização de carbono no sistema amazônico. Em sistemas dulcícolas, o enxofre orgânico pode ser o principal estoque de enxofre reduzido (Alewell \& Novak 2001), sendo a redução de sulfato menos intensa em condições oligotróficas, assim como a disponibilidade de material orgânico e a concentração de sulfato (Holmer \& Storkholm 2001). Holmer et al. (1998) mostraram que a taxa de redução de sulfato foi limitada pela baixa concentração do substrato $(\leq 25 \mu \mathrm{M})$ no sedimento abaixo de bancos de macrófitas. Esses autores sugeriram que o aumento da concentração de sulfato talvez não influencie a sua redução em sedimento com rizosfera devido à alta oxigenação, sendo maior em sedimentos profundos. Gilmour \& Henry (1991) avaliaram que a concentração ótima de sulfato para as bactérias redutoras de sulfato (BRS) que formam $\mathrm{MeHg}$ em sedimento varia entre $200-500 \mu \mathrm{M}$, mas provavelmente varia entre sistemas e, até mesmo, entre locais de um mesmo sistema em função de outros fatores.

Apesar de aparentar baixa concentração de sulfato no sistema aquático do rio Tapajós, compostos baseados em enxofre raramente são nutrientes limitantes e podem ser derivados da decomposição e exudação de plantas, ou mesmo por aplicação 
manual, que contribuem para a capacidade de ligação com o mercúrio (King et al. 2002). Swain et al. (2004) sugeriram que em sistemas pobres em sulfato, a produção de $\mathrm{MeHg}$ seria tanto função da deposição atmosférica de sulfato como de mercúrio. Mesmo em culturas puras de BRS crescendo tanto na presença quanto na ausência de sulfato, a metilação de $\mathrm{Hg}$ foi associada com a respiração de sulfato (King et al. 2000), e foram capazes de utilizar ferro, manganês e até mesmo oxigênio como receptores de elétrons durante o processo de oxidação de compostos reduzidos de enxofre (Lovley \& Phillips 1994). Em lagos inundáveis do rio Beni, localizado na Amazônia boliviana, Acha et al. $(2005,2006)$ encontraram diversas comunidades de BRS associadas a diferentes espécies de macrófitas aquáticas, e capazes de metilar e/ou demetilar Hg. A formação de $\mathrm{MeHg}$ pode estar baseada na composição da comunidade e atividade das BRS (King et al. 2000, 2002) e uma maior diversidade e metabolismo microbiano pode ocorrer durante o período de cheia junto com o aumento da biomassa de macrófitas aquáticas.

\section{BIODISPONIBILIDADE DO MERCÚRIO}

Roulet et al. (2001b) sugeriram que a geoquímica de oxihidróxidos de ferro $(\mathrm{Fe})$ e alumínio ( $\mathrm{Al}$ ) controla o acúmulo de mercúrio em solo e sedimento, porém bactérias consomem preferencialmente complexos sem carga. Os oxihidróxidos com matéria orgânica e minerais argilosos formam complexos lábeis, possibilitando maior capacidade de carrear mercúrio. Assim, a formação e dissolução dos oxihidróxidos e complexos orgânicos podem influenciar a metilação, uma vez que controlam a disponibilidade de $\mathrm{Hg}$ inorgânico (Ullrich et al. 2001). Com o ciclo de inundação na bacia do rio Tapajós, a origem do complexo associado ao $\mathrm{Hg}$ parece ser determinante na biodisponibilidade deste metal. O perifíton associado às raízes de macrófitas pode ter maior influência de solos semiterrestres durante o período de seca e cheia, do solo de Igapó durante a cheia e de solos terrestres durante as chuvas (Coelho-Souza et al. 2006b). Os sedimentos semi-aquáticos apresentam uma mistura de resíduos de plantas (sedimento húmico) junto com uma matriz argilosa, também observada no sedimento de centros de lagos inundados (sem influência do banco de macrófitas). O solo de Igapós semi-terrestres e de floresta, inundados 4-6 meses por ano, são caracterizados pela camada de material húmico bem definida abaixo do solo mineral argiloso, formado em condições restritas de drenagem (Roulet et al. 2001b). Poirier (2004) descreveu que os solos terrestres são basicamente compostos por quartzo $\left(\mathrm{SiO}_{2}\right)$, kaolinita $\left(\mathrm{Al}_{2} \mathrm{SiO}_{4}\right)$, oxihidróxidos de $\mathrm{Al}$ e $\mathrm{Fe}$ como goetita $\left(\mathrm{Fe}_{2} \mathrm{O}_{3}\right)$ e hematita $\left(\mathrm{Fe}_{2} \mathrm{O}_{3}\right)$. Nenhuma diferença foi observada entre o perfil do solo de floresta de Igapó e de sedimentos no centro e margem de lagos inundados (inclusive capim) em relação à concentração de $\mathrm{Hg}, \mathrm{Corg}, \mathrm{C} / \mathrm{N}, \mathrm{Fe}$ e Al. Entretanto, os perfis destes sedimentos apresentaram distinta relação entre as concentrações de $\mathrm{Hg}$ e $\mathrm{Fe}$, fato não observado entre $\mathrm{Hg}$ e Al (Roulet et al. 2001b).

Estudos recentes indicam que a metilação é decrescida em condições redutoras de ferro férrico possivelmente devido à adsorção de mercúrio inorgânico em oxihidróxidos de ferro. Outra suposição é o efeito do ferro ferroso, o produto da redução do ferro, que por carrear sulfitos, facilita a especiação aquosa do sulfeto mercúrico (Barkay \& WagnerDöbler 2005). A adição de oxihidróxidos de Fe(III) amorfos em sedimentos pode inibir tanto a redução de sulfato quanto a metanogênese, provavelmente devido ao maior consumo do hidrogênio e do acetato presentes no meio por bactérias redutoras de ferro (Ullrich et al. 2001). King \& Garey (1999) sugeriram que as bactérias redutoras de ferro presentes em rizomas de macrófitas aquáticas, talvez reduzam os ácidos húmicos e limitem a disponibilidade de matéria orgânica para outros microrganismos heterotróficos tanto na rizosfera quanto no sedimento. O material húmico parece ser outro importante fator ambiental na formação de $\mathrm{MeHg}$ aumentando o potencial de metilação em detritos originários de raízes de macrófitas (Lemos 2001). Lee et al. (1985) observaram que a produção do $\mathrm{MeHg}$, durante 2-4 dias a temperatura de $30{ }^{\circ} \mathrm{C}$, no escuro e, com $\mathrm{pH}$ ótimo entre 4 e 4,5, aumentou com a maior disponibilidade do íon de $\mathrm{Hg}^{2+}$ e ácidos fúlvicos, assim como com a adição de outros íons metálicos, onde a ordem catalítica foi: $\mathrm{Fe}^{3+}\left(\mathrm{Fe}^{2+}\right)>\mathrm{Cu}^{2+} \approx \mathrm{Mn}^{2+},>\mathrm{Al}^{3+}$.

Os solos argilosos de áreas desmatadas parecem reter mais facilmente os cátions provenien- 
tes da queima da floresta, particularmente cálcio e magnésio, competindo com os átomos de $\mathrm{Hg}$ e impulsionando sua lixiviação. Já os solos arenosoargilosos apresentam menor eficiência na retenção de cátions, porém maior acúmulo de fósforo orgânico. Em lagos inundados, o $\mathrm{pH}$ do solo aumentou de 4,2 a 5,2 após o desmatamento da floresta, reduzindo a associação do $\mathrm{Hg}$ com a matéria orgânica, que é favorecida em pH abaixo de 5 (Farella 2005). Assim, o pH de solos de floresta parece contribuir para a adsorção de Hg por complexos orgânicos que quando mineralizados por microrganismos, aumentam a formação de MeHg. O solo de Igapó também apresentou meio mais reduzido do que o sedimento de lago e capim (Roulet et al. 2001b). Rudd et al. (2006) concluíram que, dentro das condições testadas, a fração de mercúrio reativo foi um indicativo da quantidade de $\mathrm{Hg}$ inorgânico biodisponível para bactérias. Marvin-Dipasquale et al. (2006) concluíram que a inclusão do $\mathrm{Hg}$ (II) reativo biodisponível na modelagem da metilação bêntica, permite não somente melhor previsão da taxa de produção de $\mathrm{MeHg}$, como um melhor entendimento das interações entre os vários fatores que influenciam tanto a atividade das bactérias metiladoras quanto a disponibilidade desse $\mathrm{Hg}$ para tais bactérias. Entretanto, muitas reações biogeoquímicas estão envolvidas no processo de metilação, o que compromete a teoria do $\mathrm{Hg}$ biodisponível, dificultando um melhor entendimento do papel da biodisponibilidade do $\mathrm{Hg}$ mais reativo para metilação e sua incorporação pela biota (Lamborg et al. 2006).

\section{ORIGEM E QUALIDADE DA MATÉRIA ORGÂ- NICA}

Pacheco-Peleja (2002) reportou, na água de lagos do rio Tapajós, que as concentrações de carbono orgânico dissolvido (COD) e oxigênio dissolvido foram maiores durante o período de chuvas do que no período de seca. $\mathrm{O} \mathrm{pH}$ foi ácido-neutro e a temperatura oscilou entre 27 a $29^{\circ} \mathrm{C}$. A matéria orgânica dissolvida (MOP) pode tanto aumentar a formação de $\mathrm{MeHg}$, estimulando o crescimento microbiológico, como inibir a metilação, ao formar complexos com o $\mathrm{Hg}$ e diminuindo sua disponibilidade para microrganismos (Ravichandran 2004). O Hg(II) fresco adicionado ao sistema parece ser mais reativo do que o antigo já presente na matriz de metilação (Hintelmann et al. 2002), e não afeta o metabolismo de centenas de bactérias resistentes ao $\mathrm{Hg}$ (Barkay \& Wagner-Döbler 2005). A adição de carbono orgânico dissolvido (COD) aumenta a produção de $\mathrm{MeHg}$ em sedimentos já contendo $\mathrm{Hg}$ antigo e o $\mathrm{MeHg}$ formado parece ser liberado para a água e rede trófica (Krabbenhoft et al. 2004). Porém, altas concentrações de COD inibem a metilação, principalmente em $\mathrm{pH}$ neutro, ao formar complexos de difícil consumo (Ullrich et al. 2001).

Benner et al. (1995) observaram maior eficiência de crescimento bacteriano durante os períodos de chuvas e cheia e associaram à maior biodisponibilidade de substratos provenientes das áreas inundadas, com pouca variação espacial entre rios de água negra e branca. Em águas claras, durante a cheia, o fósforo foi o principal nutriente limitante para a produção do bacterioplâncton e a adição de glicose estimulou a produção principalmente devido à baixa qualidade do carbono já presente (Farjalla et al. 2002). A disponibilidade de nutrientes é um fator importante no controle de metilação microbiana em sistemas aquáticos (Ullich et al. 2001). O fósforo orgânico apresenta um efeito claro no uso da terra, ao se acumular na superfície do solo depois da queima da floresta e, pode estar associado com o conteúdo de carbono no solo. Já o ortofosfato, obteve maior correlação com os oxihidróxidos de ferro e alumínio. O nitrogênio disponível representou a perda mais importante em solos impactados, em comparação com solos de floresta (Farella 2005).

Amado et al. (2006) concluíram que em ecossistemas amazônicos de águas claras, as diferentes fontes de COD são degradadas fotoquimicamente com complementar ação bacteriana. Esses autores sugeriram que a mineralização bacteriana se destaca na degradação de COD autóctone enquanto a oxidação fotoquímica foi mais comum em COD alóctone. Abioticamente, o $\mathrm{Hg}(\mathrm{II})$ pode ser reduzido, como produto de transformações fotoquímicas. A fotorredução parece acontecer principalmente na formação de radicais livres orgânicos que são produzidos por fotólise do COD, oxigênio dissolvido, complexos orgânicos e, na transformação de compostos orgânicos de ácidos férricos. Já no escuro, o $\mathrm{Hg}(\mathrm{II})$ pode ser reduzido por radicais livres associados aos ácidos húmico e fúlvico (Fostier et al. 2000, Barkay \& Wagner-Döbler 2005). 


\section{A IMPORTÂNCIA DAS MACRÓFITAS AQUÁ- TICAS NA TRANSFERÊNCIA TRÓFICA DO METILMERCÚRIO}

A produção de $\mathrm{MeHg}$ e seu consumo parecem ser favorecidas durante o período de inundação (Guimarães et al. 2000a, Roulet et al. 2001b). O uso de isótopos estáveis indicou distintas origens de carbono para o perifíton associado às raízes de Paspalum repens durante o ciclo de inundação (Coelho-Souza et al. 2006b). Em lagos do rio Tapajós, assim como na assinatura isotópica do perifíton associado às raízes de Paspalum repens, a assinatura de $\delta^{13} \mathrm{C}$ em peixes variou entre os períodos de inundação e entre coletas realizadas em lagos próximos (Sampaio da Silva et al. 2005). Os peixes não predadores apresentaram maior enriquecimento de $\delta^{13} \mathrm{C}$ no período de chuvas e correlação positiva entre a concentração de $\mathrm{Hg}$ e $\delta^{15} \mathrm{~N}$. Desse modo, foi sugerido que a variabilidade do conteúdo de $\mathrm{Hg}$ em músculo de peixes pode estar relacionada com o seu tamanho e sua posição trófica. Gustin et al. (2005) sugeriram que as razões isotópicas de $\delta^{13} \mathrm{C}$ e $\delta^{15} \mathrm{~N}$ podem indicar impactos humanos na concentração de $\mathrm{Hg}$ em tecido muscular de peixes. Em sistema boreal, Montgomery et al. (2000) confirmaram a ligação trófica entre material particulado fino (MPF) e zooplâncton através da assinatura de $\delta^{13} \mathrm{C}$. Porém Kainz \& Lucotte (2002), utilizando a mesma técnica, observaram que a composição da matéria orgânica de sedimentos boreais inundados não modificou a composição bioquímica do zooplâncton e nem estava relacionada às concentrações de $\mathrm{MeHg}$.

As medidas de $\delta^{13} \mathrm{C}$ indicam, primeiramente, quais as fontes de carbono de plantas são mais importantes para o consumo na cadeia trófica, enquanto o isótopo de nitrogênio indica o nível trófico do organismo avaliado (Fry 1991). Dentro dos poucos estudos pontuais no rio Tapajós, foi observado no lago Bom Intento que o perifíton analisado apresentou variação isotópica de $\delta^{13} \mathrm{C}$ entre $-31,3$ e $-28,9 \%$ e de $\delta^{15} \mathrm{~N}$ entre 4,8 to $7,2 \%$, durante os períodos de cheia e chuvas, respectivamente (Coelho-Souza et al. 2006b). No mesmo período de coleta, a espécie de peixe detritívoro Curimata inornata apresentou variação de $\delta^{13} \mathrm{C}$ entre $-32,7$ a $-30,7 \%$ e de $\delta^{15} \mathrm{~N}$ entre $9,1 \%$ e $8,1 \%$, enquanto o onívoro Hemiodus unimaculatus obteve assinatura média de $-30 \%$ para $\delta^{13} \mathrm{C}$ e $8,8 \%$ para $\delta^{15} \mathrm{~N}$ (Sampaio da Silva et al. 2005). Apesar do aumento de nível trófico ser considerado quando há um aumento de $3 \%$ de $\delta^{15} \mathrm{~N}$ e $1 \%$ para $\delta^{13} \mathrm{C}$ (Fry 1991), mais estudos com o uso de isótopos estáveis poderão apontar o papel das macrófitas aquáticas na transferência do $\mathrm{MeHg}$ produzido em suas raízes. As espécies supracitadas podem consumir perifíton ou sua biota associada, porém são migratórias e de hábitos alimentares oportunistas, mudando suas assinaturas isotópicas espacialmente e temporalmente (BeneditoCecilio et al. 2000, Sampaio da Silva et al. 2005). Essa variação de assinatura pode estar relacionada mais com a mudança da dieta do que com a composição isotópica das plantas, uma vez que estes peixes são seletivos quanto à assimilação de carbono orgânico particulado (Benedito-Cecilio et al. 2000). Por outro lado, esse carbono pode ser acumulado por raízes de macrófitas e determinar a composição do perifíton associado, resultando na grande variação isotópica dessa matriz e na sua taxa de consumo (Coelho-Souza et al. 2006b). A concentração de $\mathrm{Hg}$ total em peixes não carnívoros foi similar à do perifíton de raízes de macrófitas aquáticas, porém com maior variabilidade (Figura 4).

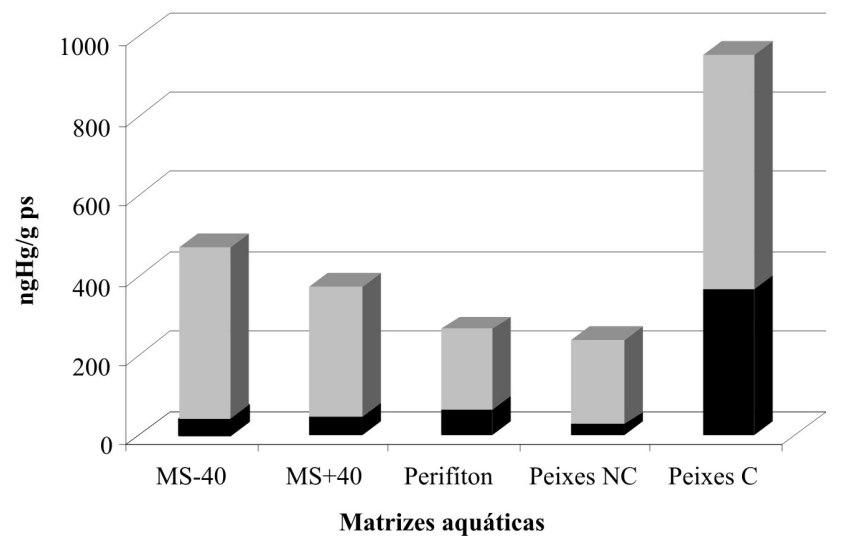

Figura 4. Concentrações de $\mathrm{Hg}$ total (ng/g ps) em distintas matrizes do meio aquático (minima em negro e máxima em cinza). $\mathrm{MS}=-40$ material em suspensão menor de 40um e +40 maior que 40um. $\mathrm{NC}=$ não carnívoro. $\mathrm{C}=$ carnívoro. Dados de Pacheco-Peleja 2002, Sampaio da Silva et al. 2005 e Coelho-Souza et al. 2006b.

\section{CONCLUSÃO}

As macrófitas parecem ser o elo entre o $\mathrm{Hg}$ inorgânico e o Hg neurotóxico uma vez que acumula e metila o Hg. A composição do perifíton associado às suas raízes parece ser determinada pela conservação da mata ciliar, uso e tipo de solo, além da época do ano. Esses fatores podem influenciar os parâmetros físico-químicos do meio aquático, biodisponibilidade 
do $\mathrm{Hg}$, produção de $\mathrm{MeHg}$ e atividade bacteriana. Os avanços nos estudos sobre o ciclo do $\mathrm{Hg}$ na bacia do rio Tapajós indicam que mais pesquisas devem ser realizadas incluindo o perifíton associado às raízes de macrófitas aquáticas.

\section{REFERÊNCIAS}

ACHA, D.; HINTELMANN, H.; PABON, C. \& ROULET, M. 2006. Mercury methylation and demethylation potentials and sulfate reducing bactéria community in an Amazonian macrophytes rhizosphere. In: XIII th Conference of Mercury as a Global Pollutant, Abstract M-205.

ACHA, D.; IÑIGUEZ, V.; ROULET, M.; GUIMARÃES, J.R.D.; LUNA, R.; ALANOCA, L. \& SANCHEZ, S. 2005. Sulfatereducing bacteria in floating macrophyte rhizospheres from an Amazonian floodplain lake in Bolivia and their association with $\mathrm{Hg}$ methylation. Applied and Environmental Microbiology, 71: 7531-7535.

ALEWELL, C. \& NOVAK, M. 2001. Spotting zones of dissimilatory sulfate reduction in a forested catchment: the ${ }^{34} \mathrm{~S}-{ }^{35} \mathrm{~S}$ approach. Environment and Pollution, 112: 369-377.

AMADO,A.M.; FARJALLA, V.F.; ESTEVESF.A.;BOZELLI, R.; ROLAND, F. \& ENRICH-PRAST, A. 2006. Complementary dissolved organic carbon removal pathways in clear-water Amazonian ecosystems: photochemical degradation and bacterial uptake. FEMS Microbiology Ecology, 56(1): 8-17.

BARKAY, T. \& WAGNER-DÖBLER, I. 2005. Microbial transformations of mercury: potentials, challenges, and achievements in controlling mercury toxicity in the environment. Advances in Applied Microbiology, 57: 1-52.

BENEDITO-CECILIO, E.; ARAÚJO-LIMA, C.A.R.M.; FORSBERG,B.R.; BITTENCOURT, M.M.\&MARTINELLI, L.C. 2000. Carbon sources of Amazon fisheries. Fisheries Management Ecology, 7: 305-315.

BENNER, R.; OPSAHL, S.; CHIN-LEO, G.; RICHEY, J. \& FORSBERG, B.R. 1995. Bacterial carbon metabolism in the Amazon River system. Limnology and Oceanography, 40: 1262-1270.

CHOI, S.C.; CHASE, T.J.R. \& BARTHA, R. 1994. Enzymatic Catalysis of Mercury Methylation by Desulfovibrio desulfuricans. Applied and Environmental Microbiology, 60(4): 1342-1346.

CLEARY, D. \& THORNTHON, I. 1994. The Environmental Impact of Gold Mining in the Brazilian Amazon. Pp 17-40. Mining and its Environmental Impact. Issues in Environmental Science and Technology 1, Royal Society of Chemistry.

COELHO-SOUZA, S.A. 2003. Formação de metilmercúrio, atividade bacteriana e sulfato-redução em raizes de macrófitas aquáticas (Rio Tapajós - PA) e fitoplâncton. Tese de Mestrado. UFRJ, Rio de Janeiro, Brasil. 73p.

COELHO-SOUZA, S.A.; GUIMARÃES, J.R.D.; MAURO, J.B.N.; MIRANDA, M.R. \& AZEVEDO, S.F.M.O. 2006a. Mercury methylation and bacterial activity associated to tropical phytoplankton. Science of the Total Environment, 364: 188-199.

COELHO-SOUZA, S.A.; GUIMARÃES, J.R.D.; MAURO, J.B.N.; POIRIER, H.; LUCOTTE, M. \& MERGLER, D. 2006b. The importance of aquatic macrophyte roots in $\mathrm{Hg}$ cycle in Tapajós river basin, Brazilian Amazon. In: Proceedings of the XIII th Conference of Mercury as a Global Pollutant. Abstract M-110.

COMPEAU, G. \& BARTHA, R. 1985. Sulfate reducer bacteria: principal methylators of mercury in anoxic estuarine sediments. Applied and Environmental Microbiology, 50: 498-502.

CORDEIRO, R.C.; TURCQ, B.; RIBEIRO, M.G.; LACERDA, L.D.; CAPITÂNEOJ.; OLIVEIRADASILVAA.; SIFEDDINE A. \& TURCQ P.M. 2002. Forest fire and mercury deposition in an intense land use change region in the Brazilian Amazon (Alta Floresta, MT). Science of the Total Environment, 293: 247-256.

CRAIG, P.J. 1985. Organometallic Compounds in the Environment. Longman, London, England, 367p.

FARELLA N. 2005. Les fermes de la région frontière du Tapajós en Amazonie brésilienne: relations entre les origines familiales, les pratiques agricoles, les impacts sur les sols et le déboisement. Tese de Doutorado. UQAM, Quebec, Montreal, Canada. 195p.

FARJALLA, V.F.; ESTEVES, F.A.; BOZELLI, R.L. \& ROLAND F. 2002. Nutrient limitation of bacterial production in clear water Amazonian ecosystems. Hydrobiology, 489: 197-205.

FOSTIER A.H.; FORTI, M.C.; GUIMARÃES, J.R.D.; MELFI, A.J.; BOULET, R.; ESPIRITO SANTO, C.M. \& KRUG, F.J. 2000. Mercury fluxes in a natural forested Amazonian catchment (Serra do Navio, Amapá State, Brazil). Science of the Total Environment, 260: 201-211.

FRY, B. 1991. Stable isotope diagrams of freshwater food webs. Ecology, 72: 2293-2297.

FURCH K. \& JUNK W.J. 1997. Physicochemical conditions in the floodplains. Pp 69-108. In: Junk (ed.) The central Amazon floodplain (126), Springer-Verlag press, Berlin Heidelberg.

GILMOUR, C.C. \& HENRY, E. 1991. Mercury Methylation in Aquatic Systems Affected by Acid Deposition. Environment Pollution, 71: 131-169.

GUIMARÃES, J.R.D.; MEILI, M.; MALM, O. \& BRITO, E.M.S. 
1998. Hg methylation in sediments and floating meadows of a tropical lake in Pantanal floodplain, Brazil. Science of the Total Environment, 213: 165-175.

GUIMARÃES, J.R.D.; ROULET, M.; LUCOTTE, M. \& MERGLER, D. 2000a. Mercury methylation along a lakeforest transect in the Tapajós river floodplain, Brazilian Amazon: seasonal and vertical variations. Science of the Total Environment, 261: 91-98.

GUIMARÃES, J.R.D.; MEILI, M.; HYLANDER, L.D.; SILVA, E.D.E.; ROULET, M.; MAURO, J.B.N. \& DE LEMOS, R.A. 2000b. Mercury net methylation in five tropical flood plain regions of Brazil: high in the root zone of floating macrophyte mats but low in surface sediments and flooded soils. Science of the Total Environment, 261: 99-107.

GUIMARÃES, J.R.D.; MAURO, J.B.N.; COELHOSOUZA, S.A. \& POIRIER, H. 2004. Study of methylation sites and factors in contaminated aquatic systems in the Amazon using an optimized radiochemical technique. Pp 17-27. In: Health impact of mercury cycling in contaminated environments studied by nuclear techniques. United Nations IAEA.

GUIMARÃES, J.R.D.; ROULET, M.; INIGUEZ, V.; MIRANDA, M.R.; EVANGELISTA, F.S.B. \& CORREA, R.R.S. 2006. $\mathrm{Hg}$ methylation and the microbial consortium in sediment and in periphyton of tropical macrophytes: effect of different inhibitors. In: Proceedings of the XIII th Conference of Mercury as a Global Pollutant. Abstract M-111.

GUSTIN, M.S.; SAITO, L. \& PEACOCK, M. 2005. Anthropogenic impacts on mercury concentrations and nitrogen and carbon isotope ratios in fish muscle tissue of the Truckee river watershed, Nevada, USA. Science of the Total Environment, 347: 282-94.

HINTELMANN, H.; HARRIS, R.; HEYES, A.; HURLEY, J.P.; KELLY, C.A.; KRABBENHOFT, D.P.; LINDBERG, S.; RUDD, J.W.; SCOTT, K.J. \& ST LOUIS, V.L. 2002. Reactivity and mobility of new and old mercury deposition in a boreal forest ecosystem during the first year of the METAALICUS study. Mercury experiment to asses atmospheric loading in Canada and the US. Environmental Science Technology, 36: 5034-5040.

HOLMER, M.; JENSEN, H.S.; CHRISTENSEN, K.K.; WIGAND, C. \& ANDERSEN, F.O. 1998. Sulfate reduction in lake sediments inhabited by the isoetid macrophytes Littorella uniflora and Isoetes lacustris. Aquatic Botany, 60: 317-324.

HOLMER, M. \& STORKHOLM, P. 2001. Sulphate reduction and sulphur cycling in lake sediments: a review. Freshwater Biology, 46: 431-451.
IPCS (International Programme on Chemical Safety). 1990. Methylmercury - Environmental Health Criteria, 101. World Health Organization (WHO), Geneva. 144p.

KAINZ, M. \& LUCOTTE, M. 2002. Can flooded organic matter from sediments predict mercury concentrations in zooplankton of a perturbated lake? Science of the Total Environment, 293: 151-161.

KELLY, C.A.; RUDD, J.W.M.; LOUIS, V.L. \& HEYES, A. 1995. Is total mercury concentration a good predictor of methyl mercury concentration in aquatic systems? Water Air Soil Pollutants, 80:715.

KING, G.M. \& GAREY. M.A. 1999. Ferric iron reduction by bacteria associated with the roots of freshwater and marine macrophytes. Applied Environmental Microbiology, 65: 4393-4398.

KING, J.K.; KOSTKA, J.E.; FRISCHER, M.E. \& SAUNDERS, F.M. 2000. Sulfate-reducing bacteria methylate mercury at variable rates in pure culture and in marine sediments. Applied Environmental Microbiology, 66: 2430-2437.

KING, J.K.; KOSTKA, J.E.; FRISCHER, M.E.; SAUNDERS, F.M. \& JAHNKE, R.A. 2001. A quantitative relationship that demonstrates mercury methylation rates in marine sediments are based on the community composition and activity of sulfate-reducing bacteria. Environment Science Technology, 35: 2491-2496.

KING, J.K.; HARMON, S.M.; FU, T.T. \& GLADDEN, J.B. 2002. Mercury removal, methylmercury formation, and sulfate-reducing bacteria profiles in wetland mesocosms. Chemosphere, 46: 859-870.

KRABBENHOFT, D.; GILMOUR, C.; OREM, W. \& AIKEN, G. 2004. Unraveling the complexities of mercury methylation in the Everglades: the use of mesocosms to test the effects of "new" mercury, sulfate, and dissolved organic carbon. $R M Z$ Materials Geoenvironment, 51: 1150-1151.

LACERDA, L.D. 1995. Amazon mercury emissions. Nature, 374: 20-21.

LACERDA, L.D.; SOUZA, M. \& RIBEIRO, M.G. 2004. The effects of land use change on mercury distribution in soils of Alta Floresta, Southern Amazon. Environmental Pollution, 129: $247-255$.

LAMBORG, C.; SCHMIDT, C.H. \& FITZGERALD, W. 2006. Does "Reactive Hg" Really Have Any Meaning? In: Proceedings of the XIII th Conference of Mercury as a Global Pollutant. Madison, USA. Abstract S-875.

LEE, Y.H.; HULTBERG, H. \& ANDERSSON, I. 1985. Catalytic effect of various metal ions on the methylation of mercury in the presence of humic substances. Water Air Soil Pollutants, 25: 391-400. 
LEMOS, R.M.A. 2001. Influencia da decomposição de macrófitas aquáticas na dinâmica do mercúrio em áreas alagáveis - com ênfase no processo de metilação do Hg. Tese de Doutorado. UFSC, São Carlos, SP, Brasil. 153p.

LINDQVIST, O. 1985. Atmospheric mercury - a review. Tellus, 37: 136-159.

LOVLEY, D.R. \& PHILLIPS, E.J.P. 1994. Novel process for anaerobic sulfate production from elemental sulfur by sulfatereducing bacteria. Applied Environment Microbiology, 60: 2394-2399.

MALM, O. 1998. Gold mining as a source of mercury exposure in the Brazilian Amazon. Environment Research, 77: 73-78.

MARVIN-DIPASQUALE, M.; HALL B.D.; FLANDERS J.R.; LADIZINSKI, N.; AGEE, J.L.; KIEU L.H. \& WINDHAMMYER, L. 2006. Ecosystem Investigations of Benthic Methylmercury Production: A Tin-Reduction Approach for Assessing the Inorganic Mercury Pool Available for Methylation. In: Proceedings of the XIII th Conference of Mercury as a Global Pollutant. Abstract S-404.

MAURO, J.B.N.; GUIMARÃES, J.R.D. \& MELAMED, R. 1999. Mercury Methylation in a Tropical Macrophyte: Influence of Abiotic Parameters. Applied Organometallic Chemistry, 13: 631-636.

MAURO, J.B.N.; GUIMARÃES, J.R.D. \& MELAMED, R. 2001. Mercury methylation in macrophyte roots of tropical lake. Water Air Soil Pollutants, 127: 271-280.

MAURO, J.B.N.; GUIMARÃES, J.R.D.; HINTELMANN, H.; WATRAS, C.J.; HAACK, E.A. \& COELHO-SOUZA, S.A. 2002. Mercury methylation in macrophytes, periphyton, and water comparative studies with stable and radio-mercury additions. Analytical and Bioanalytical Chemistry, 374: 983-989.

MELAMED, R.; VILLAS BÔAS, R.C.; GONÇALVES, G.O. \& PAIVA, E.C. 1997. Mechanisms of Physical-Chemical Interaction of Mercury with River Sediments from a Gold Mining Region in Brazil: Relative Mobility of Mercury Species. Journal of Geochemical Exploration, 58: 119-124.

MIRANDA, R.M.; GUIMARÃES, J.R.D.; ROULET, M.; ACHA, D.; COELHO-SOUZA, S.A.; MAURO, J.B.N. \& INIGUEZ, V. 2004. Mercury methylation and bacterial activity in macrophyte-associated periphyton in floodplain lakes of the Amazon basin. RMZ Materials and Geoenvironment, 51: 1218-1220.

MONTGOMERY, S.; LUCOTTE, M. \& COURNOYER, L. 2000. The use of stable carbon isotopes to evaluate the importance of fine suspended particulate matter in the transfer of methylmercury to biota in boreal flooded environments. Science of Total Environment, 261: 33-41.

NIELSEN, L.P.; ENRICH-PRAST, A. \& ESTEVES, F.A. 2004.
Pathways of organic matter mineralization and nitrogen regeneration in the sediment of five tropical lakes. Acta Limnology Brasiliensis, 16: 1-9.

PACHECO-PELEJA, J.R. 2002. Os fatores que influem no nivel de mercúrio $(\mathrm{Hg})$ na água e plâncton de lagos associados aos rios Tapajós e Negro. Tese de Mestrado. INPA/UFA, Manaus, AM, Brasil. 75p.

PASSOS, C.J.; MERGLER, D.; GASPAR, E.; MORAIS, S.; LUCOTTE, M.; LARRIBE, F.; DAVIDSON, R. \& GROSBOIS, S. 2003. Eating tropical fruit reduces mercury exposure from fish consumption in the Brazilian Amazon. Environmental Research, 93: 123-130.

PFEIFFER, W.C.; LACERDA, L.D.; SALOMONS, W. \& MALM, O. 1993. Environmental fate of mercury from gold mining in the Brazilian Amazon. Environmental Review, 1: 26-37.

POIRIER, H. 2004. L'impact de l'utilisation du territoire sur la distribuition du mercure dans les sols amazoniens: une approche toposéquentielle. Tese de Mestrado. UQAM, Quebec, Montreal, Canada. 86pp.

RAVICHANDRAN, M. 2004. Interactions between mercury and dissolved organic matter - a review. Chemosphere, 55: 319-331.

REGNELL, O.\& TUNLID, A. 1991. Laboratory study of chemical speciation of mercury in lake sediment and water under aerobic and anaerobic conditions. Applied Environmental Microbiology, 57: 789-795.

ROSSER, H.R. \& HAMILTON, W.A. 1983. Simple assay for accurate determination of $\left[{ }^{35} \mathrm{~S}\right]$ sulfate reduction activity. Applied Environmental Microbiology, 45: 1956-1959.

ROULET, M. \& LUCOTTE, M. 1995. Geochemistry of mercury in pristine and flooded ferraltic soils of a tropical rain forest in French Guiana, south America. Water, Air and Soil Pollution, 80: 1079-1088.

ROULET, M.; LUCOTTE, M.; CANUEL, R.; RHEUALT, I.; TRAN, S.; GOCH, Y.G.D.; FARELLA, N.; DO VALE, R.S.; PASSOS, C.J.D.; DA SILVA, E.D.; MERGLER, D. \& AMORIM, M. 1998a. Distribution and partition of total mercury in waters of the Tapajós river basin, brazilian Amazon. Science of Total Environment, 213: 203-211.

ROULET, M.; LUCOTTE M.; SAINT-AUBIN, A.; TRAN, S.; RHÉAULT, I.; FARELLA, N.; DE JESUS DA SILVA, F.; DEZENCOURT J.; SOUSA-PASSOS, C.J.; SANTOS SOARES, G.; GUIMARÃES, J.R.D.; MERGLER, D. \& AMORIM, M. 1998b. The geochemistry of mercury in central Amazonian soils developed on the Alter-do-Chão formation of the lower Tapajós river valley, Pará state, Brazil. Science of Total Environment, 223: 1-24. 
ROULET, M.; LUCOTTE, M.; FARELLA, N.; SERIQUE, G.; COELHO, H.; PASSOS, C.J.D.; DA SILVA, E.D.; DE ANDRADE, P.S.; MERGLER, D.; GUIMARÃES, J.R.D. \& AMORIM, M. 1999. Effects of recent human colonization on the presence of mercury in Amazonian ecosystems. Water Air Soil Pollution, 112: 297-313.

ROULET, M.; LUCOTTE, M.; CANUEL, R.; FARELLA, N.; GOCH, Y.G.F.; PACHECO-PELEJA, J.R.; GUIMARÃES, J.R.D.; MERGLER, D. \& AMORIM, M. 2001a. Spatiotemporal geochemistry of mercury in waters of the Tapajós and Amazon rivers, Brazil. Limnology Oceanography, 46(5): 1141-1157.

ROULET, M.; GUIMARÃES, J.R.D \& LUCOTTE, M. $2001 \mathrm{~b}$. Methylmercury production and accumulation in sediments and soils of an Amazon floodplain- effect of seasonal inundation. Water Air Soil Pollution, 128: 41-60.

RUDD, J.W.M.; KELLY, C.A.; BLOOM, N.S. \& HOLOKA, M.H. 2006. Is Reactive Mercury a Good Indicator of the Bioavailability of Mercury to Bacteria? In: Proceedings of the XIII th Conference of Mercury as a Global Pollutant. Abstract S-789.

SAMPAIO DA SILVA, D.; LUCOTTE, M.; ROULET, M.; POIRIER H.; MERGLER D.; OLIVEIRA SANTOS, E. \& CROSSA M. 2005. Trophic structure and bioaccumulation of mercury in fish of three natural lakes of the Brazilian Amazon. Water Air Soil Pollution, 165: 77-94.

SWAIN, E.; ENGSTROM, D.; JEREMIASON, J.; NATER, E.; ALMENDINGER, J.; JOHNSON, B. \& MONSON, B. 2004. Ecosystem-scale sulfate additions enhance mercury methylation in an experimental wetland. RMZ Materials Geoenvironment, 51: 492.

ULLRICH, S.M.; TANTON, T.W. \& ABDRASHITOVA, S.A. 2001. Mercury in the aquatic environment: a review of factors affecting methylation. Critical Review. Environmental Science Technology, 31: 241-293.

ULRICH, G.A.; KRUMHOLZ, L.R. \& SUFLITA, J.M. 1997. A rapid and simple method for estimating sulfate reduction activity and quantifying inorganic sulfides. Applied Environmental Microbiology, 63: 1627-1630.

VEIGA, M.M.; MEECH, J.A. \& ONATE, N. 1994. Mercury pollution from deforestation. Nature, 368: 816-817.

VILLAS BÔAS, R.C.; BEINHOFF, C. \& SILVA, A.R. 2001. Mercury in Tapajós basin. CNPq/CYTED Press, Rio de Janeiro. 198p.

WEBER, J.H. 1993. Review of possible paths for abiotic methylation of mercury (II) in the aquatic environment. Chemosphere, 26: 2063-2077. 